computers do very well against any but well- versed IM strength players.

Well, the tournament in The Hague was won by two human players who are not at all of IM strength. When analyzing the games, not just gloating over the results, it becomes evident that the reasons for their victory are that these human beings took their opponents seriously and refrained from experimentation.

I think you are right in saying that computers are still incapable of playing a well-conceived strategic game. And this is also the reason why I still believe, as I stated four years ago, that I have little to fear from computers, even though I don't play much anymore. It will take ages, if ever, before a computer is capable of beating a good human chess-player under tournament conditions. (In blitz chess and rapid chess computers may win some games.)

\title{
MUCH TO FEAR FROM CHESS COMPUTERS
}

\author{
Prof. dr. H. Berliner \\ Computer Science Department \\ Carnegie-Mellon University \\ Pittsburgh, PA 15213 \\ USA
}

"After reading Mr. Bakker's note several times, I am at a loss to understand what it is about. My only explanation is that either:

1) he is upset at the last paragraph of my article, or

2) he really does not understand too much about chess.

I will reject the latter as an explanation since he seems to be a master level player. Now let us come down to the crux of the matter. Mr. Bakker made a statement in the open literature (ICCA Journal, 1985 [Vol. 8, No. 4, p. 260]) that "he did not expect to have anything to fear from computers for the next 5 years". That was based on a single encounter with Cray Blitz, a program that all connoisseurs know has done miserably against human competition in the Fredkin matches. Therefore, I found it insulting to have the whole field judged by the performance of Cray Blitz, especially at a time when Hitech had just won the ACM tournament with a perfect score.

Now one could take issue with what "nothing to fear" means, but I believe all will interpret the statement to mean that he does not expect to lose to computers at least until 1990. However, I challenged him to turn his expression of confidence into a bet, and he declined this (ICCA Journal, Vol. 9, No. 2, p. 111 and 125). It seems rather clear to me that he or his backers would lose whatever money they wagered, very likely against Hitech, and certainly to Deep Thought.

So why is Mr. Bakker changing the argument to "computers beating good players" all of a sudden. "Good players" is as non-quantitive as "nothing to fear". Mr. Bakker seems to revel in making statements that are imprecise, and when one tries to challenge him to make them precise, he quickly runs away.

That is all I have to say on the matter. If Mr. Bakker wishes to make ridiculous statements in the press, then he must be willing to "put his money where his mouth is". Failing to do that, he appears to be falling back on writing meaningless letters to the editor."

\section{HELP WANTED: KRP(a)KB}

\author{
Lars Falk \\ Tegnérgatan $34 \mathrm{~B}$ \\ 75227 Uppsala \\ Sweden
}

From Dr. Lars Falk, we received the following suggestion for exploiting a database innovatively. The endgame considered is $\mathrm{KRP}(\mathrm{a}) \mathrm{KB}$. Quite recently dr. Falk discovered that a Russian composer, Rezvov, has found a complicated win in this endgame based on a series of Zugzwang positions. To quote him verbatim: 